\title{
Clinical Management of Lameness Due to Foot Rot in a Goat
}

\author{
Praveen Kumar ${ }^{1 *}$, Anup Yadav ${ }^{1}$, Lokesh $^{1}$, Umed Singh Mehra ${ }^{1}$, \\ Rajendra Yadav ${ }^{2}$ and Pankaj Kumar ${ }^{3}$ \\ ${ }^{1}$ Department of Animal Husbandry and Dairying, Govt. of Haryana, India \\ ${ }^{2}$ Regional Veterinary Diagnostic and Extension Centre, Mahendergarh (LUVAS, Hisar), \\ Haryana, India \\ ${ }^{3}$ Disease Investigation Laboratory, Rohtak (LUVAS, Hisar), Haryana, India
}

*Corresponding author

\section{A B S T R A C T}

\section{Keywords \\ Foot rot, Lameness, Hygiene \\ Article Info \\ Accepted: \\ 22 October 2018 \\ Available Online: \\ 10 November 2018}

The present case report is about foot rot in an adult female goat clinically manifested in the form of moistened hoof, showed sign of sloughing off, spread foul smelling and pus oozing necrotic pododermatitis resulting in non-weight bearing lameness in right forelimb. The affected goat was successfully treated by using local dressing and parenteral administration of antibiotic, analgesic and multivitamin for three days.

\section{Introduction}

Foot diseases are major causes of lameness in small ruminants and responsible for great economic losses, due to reduced forage intake, less body weight gains and milk production, decreased reproduction rates, and premature culling of animals (Tadich and Hernandez, 2000; Pugh, 2004). Foot rot is one of the most frequent, debilitating and highly contagious diseases of cattle, sheep and goats causing significant loss in animal production, and is considered as a serious emerging problem of animals throughout the world (Kaler and Green, 2008; Zhou et al., 2009). The disease characterized by foul smelling, inflammatory exudates and necrosis of the epidermal tissues of the hoof, and is manifested by complete destruction of the hard keratin layer of the hoof which in most cases results to lameness (Bitrus et al., 2017).

Highly virulent form of the foot rot is considered as an economically important disease of goats and sheep, and is expensive and difficult to manage as compared to the mild form, which generally does not require much intervention (Wani and Samanta, 2006). The disease is caused by the simultaneous actions Fusobacterium necrophorum and Dichelobacter nodosus, which involved in the induction and development of the disease 
process and the agent of transmission (Raadsma and Egerton, 2013). The disease transmission process of foot rot is dynamic and complex, involving infection with more than one etiological agents and often complicated or enhanced by environmental factors, host immunity, genetics, stocking rate, nutrition, frequent or continuous rainfall for several weeks and low temperature (Bennett et al., 2009; Bitrus et al., 2017). Studies have indicated that wet season influenced the susceptibility of foot rot either by changing the biology of the disease causing agent or by changing the physical structure of the hoof making it more vulnerable to attacks (Raadsma and Egerton, 2013), that's why outbreaks of the disease mostly reported during the rainy season (Bitrus et al., 2017). The lesions in goats are less severe than sheep, but may result in significant lameness (Pugh, 2004). The impaction of the interdigital space with feces, mud, and grass may cause a loss of skin integrity allowing invasion by $F$. necrophorum causing interdigital dermatitis (Winter, 2008).

Deeper lesions may involve a purulent infection with a foot abscess at the distal interphalangeal joint due to Archanobacterium pyogenes or other pyogenic bacteria causing foot abscess (Riet-Correa, 2007). Selective breeding, quarantine, foot paring with zinc, use of appropriate antibiotics and vaccination are various control measures that have proven to be very effective in reducing the onset and severity of foot rot, but very expensive and difficult to maintain and even employing these methods is also not a guarantee that the disease might not reoccur again (Bennett et al., 2009). Most studies of foot rot involve sheep, but goat can also be infected and there is transmission between sheep and goats (Ghimire et al., 1999). The present case report describes the therapeutic management of a clinical case of lameness due to foot rot in a goat.

\section{Case history and clinical observations}

A 3 years old adult female goat was presented to the Government Veterinary Hospital, Hudina (Mahendergarh, Haryana) with the history of injury during grazing at the right forelimb resulting in non-weight bearing lameness.

The condition of the animal was worsens due to negligence of the owner goat remains untreated for last 5 days. There is also history of in appetence for last 3 days. Recording of vital parameters revealed rectal body temperature of $104.2^{0} \mathrm{~F}$, pulse rate of 82 beats/minute and respiratory rate of 32 cycles/minute. Thorough clinical examination of the right forelimb revealed moistened hoof, showed sign of sloughing off, spread foul smelling andpus oozing necrotic pododermatitis (Fig. 1). Almost similar findings were observed by Ghimire et al., (1999) and Bitrus et al., (2017) in goats affected with foot rot. Based on the history and detailed clinical examination, the goat was diagnosed to be suffered from foot rot in right forelimb.

\section{Therapeutic management and recovery}

For the clinical management of foot rot in the presented goat, the hoof was thoroughly rinsed with normal saline solution and cleaned with cotton to remove the dust and dirt present over there on wound. After cleaning, topical antiseptic spray (Topicure) was applied which also acts as fly repellent. Parenterally goat was administered with Strepto-penicillin (Inj. Dicrysticin) @ $5 \mathrm{mg} / \mathrm{kg}$ body weight intramuscularly as an antibiotic and Flunixinmeglumine (Inj. Megludyne) @ 2.2 $\mathrm{mg} / \mathrm{kg}$ body weight by intramuscular route as an anti-inflammatory, analgesic and antipyretic agent for 3 days. Multivitamin in the form of inj. Tribivet @ $3 \mathrm{ml}$ intramuscularly was also given for 3 days. 
Fig.1 Right forelimb of the goat affected with foot rot

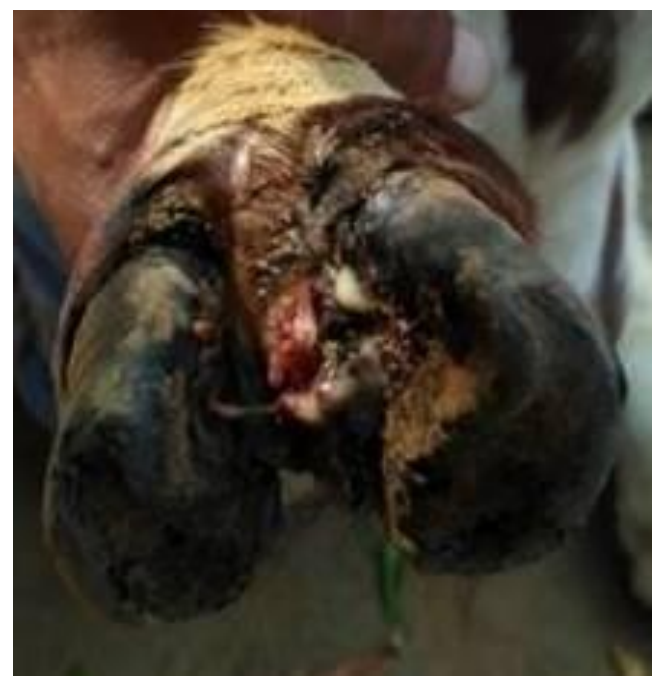

Fig.2 Right forelimb of the goat after recovery from foot rot

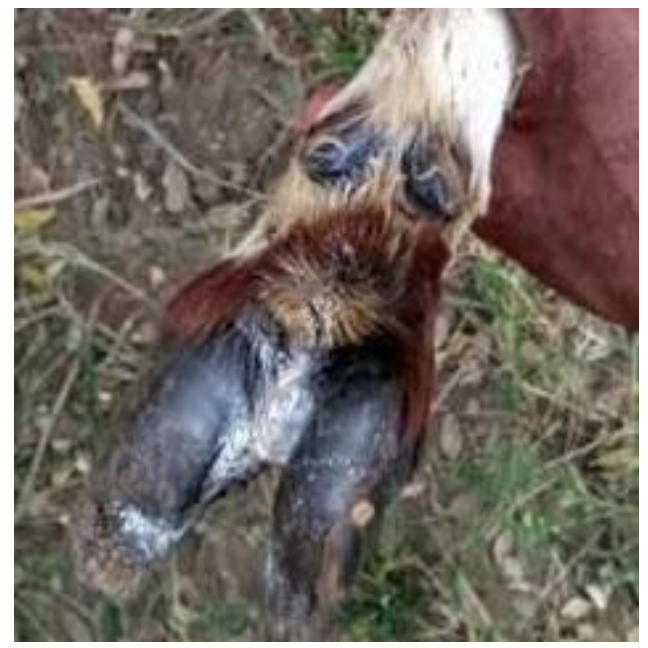

The owner was advised to keep the animal on a cleaned floor and local application of topical antiseptic spray on the wound 2-3 times a day till recovery. Previously, Bitrus et al., (2017) have also adopted same line of treatment with successful results for therapeutic management of foot rot in goats. After 3 days of treatment there was remarkable improvement and the goat was fully recovered after 5 days, which was evidenced by recovery of foot rot wound (Fig. 2), weight bearing on right forelimb, normal vital parameters and normal feed intake by the animal.

\section{Results and Discussion}

Foot rot is one of the leading causes of foot diseases in goats and sheep. Diseases associated with foot are the major causes of lameness in small ruminants and responsible for significant financial loss (Bitrus et al., 2017). Loss due to these diseases may be manifested in the form of reduction in feed intake, decrease in body weight, decrease in production, reduction in milk yield and increased rate of premature culling of animals (Tadich and Hernandez, 2000; Aguiar et al., 
2011). Dirty environment encourages the impaction of the interdigital spaces of the hoof with mud, feces and grass may result to loss in the integrity of skin, thus giving room for invasion of the digits by $F$. necrophorum causing severe dermatitis and subsequently lameness (Winter, 2008). Exposure of the feet for a long period of time to a relatively humid environment, wet pastures, urine and faeces of infected animals greatly enhance the onset and spread of the disease between animals (Aguiar et al., 2011). To reduce these economic losses to the livestock farmers and improving animal welfare, early diagnosis, proper therapeutic management and above all preventive measures for foot rot are very essential. Various studies have shown that microorganisms responsible for foot rot cannot survive for more than 10 days in the environment (Green and George, 2008), so frequent cleaning of the animal farm area can help to reduce the onset and severity of disease (Bitrus et al., 2017). To reduce the onset and severity of foot rot, there is in need of a holistic approach towards preventing the predisposing factors (Abbott and Lewis, 2005).

From the present case report it can be concluded that sometimes foot injuries in goats followed by negligence of owner and presence of favourable environmental conditions in the form of moisture and poor hygiene may results in foot rot leading to lameness. So, such problems should be timely addressed by the animal owners and veterinarians to prevent the economic losses as well as for improving animal welfare.

\section{References}

Abbott, K.A. and Lewis, C.J. (2005). Current approaches to the management of ovine footrot. Vet. J. 169: 28-41.

Aguiar, G., Simoes, S.V.D., Silva, T.R., Assis, A.C.O., Medeiros, J., Garino, J.F. and Riet-Correa, F. (2011). Foot rot and other foot diseases of goat and sheep in the semiarid region of northeastern Brazil. Pesquisa Veterinaria Brasileira. 31: 879-884.

Bennett, G., Hickford, J., Sedcole, R. and Zhou, H. (2009). Dichelobacter nodosus, Fusobacterium necrophorum and the epidemiology of foot rot. Anaerobe. 15: 173-176.

Bitrus, A.A., Abba, Y., Jesse, F.F.A., Yi, L.M., Teoh, R., Sadiq, M.A., Chung, E.L.T., Lila, M.A.M. and Haron, A.W. (2017). Clinical management of foot rot in goats: A case report of lameness. $J$. Adv. Vet. Anim. Res. 4(1): 110-116.

Ghimire, S.C., Egerton, J.R. and Dhungyel, O.P. (1999). Transmission of virulent footrot between sheep and goats. Australian Vet. J. 77: 450-453.

Green, L.E. and George, T.R.N. (2008). Assessment of current knowledge of footrot in sheep with particular reference to Dichelobacter nodosus and implications for elimination or control strategies for sheep in Great Britain.Vet. J.175: 173-180.

Kaler, J. and Green, L.E. (2008). Naming and recognition of six foot lesions of sheep using written and pictorial information: A study of 809 English sheep farmers. Prev. Vet. Med. 83(1): 52-64.

Pugh, D.G. (2004). Enfermidades do SistemaMúsculoEsqueletico: Clinica de caprinoseovinos. Roca, Sao Paulo. pp: 252-256.

Raadsma, H.W. and Egerton, J.R. (2013). A review of foot rot in sheep: aetiology, risk factors and control methods. Livestock Sci. 156: 106-114.

Riet-Correa, F. (2007). Abscesso de pe. In: Riet-Correa, F., Schild, A.L., Lemos, R.A.A. and Borges, J.R.J. (Eds), Doencas de Ruminantes e Equinos. pp: 199-201. 
Tadich, N. and Hernandez, M. (2000). Prevalencia de lesionespodales en ovinos de 25 explotaciones familiares de la provincia de Valdivia, Chile. Archivos de Medicina Veterinaria. 32: 63-74.

Wani, S.A. and Samanta, I. (2006). Current understanding of the aetiology and laboratory diagnosis of foot rot. Vet. $J$. 171: 421-428.
Winter, A.C. (2008). Lameness in sheep. Small Ruminant Res. 76: 149-153.

Zhou, H., Bennett, G. and Hickford, J.G.H. (2009). Variation in Fusobacterium necrophorum strains present on the hooves of foot rot infected sheep, goats and cattle. Vet. Microbiol. 135: 363367.

\section{How to cite this article:}

Praveen Kumar, Anup Yadav, Lokesh, Umed Singh Mehra, Rajendra Yadav and Pankaj Kumar. 2018. Clinical Management of Lameness Due to Foot Rot in a Goat. Int.J.Curr.Microbiol.App.Sci. 7(11): 2984-2988. doi: https://doi.org/10.20546/ijcmas.2018.711.342 